\title{
Some indices of metabolism in young cows suffering from ketosis
}

\author{
Aleksey Trebukhov ${ }^{1, *}$, Nadezhda Momot $^{2}$, Yuliya Kolina ${ }^{2}$, Yuliya Chekunkova ${ }^{3}$, and \\ Svetlana Terebova ${ }^{2}$ \\ ${ }^{1}$ Altai State Agricultural University, 656049, Barnaul, Russian Federation \\ ${ }^{2}$ Primorskaya State Academy of Agriculture, 692510, Ussuriysk, Russian Federation \\ ${ }^{3}$ Federal Altai Scientific Centre of Agro-BioTechnologies, 656910, Barnaul, Russian Federation
}

\begin{abstract}
The key sector that ensures the country's food security is a comprehensive enhancement of livestock raising, including animal husbandry. The intensification of dairy production leads to increased metabolic stress in animals. Under such conditions, any technological failure can result in a disorder of the metabolism in cows and the development of metabolic diseases, including ketosis (acetonemia). Ketone bodies in the calf's body produce an intoxicating effect on its body. The purpose of the study was to analyze the metabolism of young animals (calves) from cows with ketosis. The studies were performed on two groups of newborn young black-and-white breeds. In the biochemical assay of blood, the indicators of protein metabolism (total protein, albumins, globulins), glucose, acetone (ketone) bodies, triglycerides were considered, which were fulfilled on the selected young animals at the age of 3,10 and 15 days. It was revealed that the condition of the metabolic processes in the body of young cows with ketosis differs considerably from the studied indicators of the metabolism of young cows of healthy cattle. By the 15th day of life, the following indicators were found in the blood of young cows with ketosis: total protein- $56.3 \pm 2.7 \mathrm{~g} \mathrm{/} 1$, albumins$57.40 \pm 4.14 \%$, betta-globulins $-20.59 \pm 5.84 \%$, gamma-globulins- $11.42 \pm 1.66$ $\%$, triglycerides- $0.44 \pm 0.02 \mathrm{mmol} / \mathrm{l}$, acetone bodies- $1.26 \pm 0.06 \mathrm{mmol} / \mathrm{l}$, glucose-5.54 $\pm 0.25 \mathrm{mmol} / 1$. Conclusion: the calves with metabolic pathology are born from cows with ketosis. It is characterized by dysproteinemia, a high content of ketones and a lower concentration of triglycerides in the blood comparing to the similar animals born from healthy cows.
\end{abstract}

\section{Introduction}

In the conditions of active import substitution, the demands on the agro-industrial sector of the country are increasing. A key area that provides the country's food security is the intensive development of domestic animal husbandry [1,2]. The implementation of this

\footnotetext{
* Corresponding author: aleks_tav@mail.ru
} 
trend is a multi-factorial challenge, which involves a high intensification of meat and dairy production.

At the same time, the intensification of production leads to the stress of metabolism in animals. Under such conditions, any technological failure can result in a serious metabolic disorder in dairy cattle, which means the development of metabolic diseases [3-5].

Acetonemia takes a special place among these diseases. The disease is diagnosed more often in the prenatal period, the first days and weeks of delivery, often without pronounced clinical signs. Within this period, the cow's body requires the maximum amount of energy and is extremely demanding on the diet composition. Its imbalance in the main components, minerals, and vitamins ensures the conditions for the emergence of a ketogenic situation [6-9]. Fatness in cows above average is regarded as a factor promoting the development of the disease [10]. The large amounts of ketones produced in the body are a typical feature of the disease [11]. Ketones are made up of several organic substances, some of which are less toxic and may be efficiently metabolized in the body. Others are more toxic, like acetone. Acetone bodies, without a threshold concentration, pass through the blood-placental barrier by diffusion and are released with milk from the cow, causing poisoning of the calf, both in the intrauterine and extrauterine (early postnatal) life [12]. In the neonatal period, research indicates low tolerance and high morbidity of young animals from cows with metabolic pathologies and diseases of various etiologies [13-14].

To this end, the purpose of our work was to analyze the metabolism of young animals (calves) from cows with ketosis.

\section{Materials and methods}

The studies were performed on calves similar to the black-and-white breed at the age of 3 days to 15 days after birth. The investigation took place on the basis of instructional farm "Prigorodny in winter-spring time. Laboratory studies were performed at the Department of Therapy and Pharmacology of the Altai State Agrarian University and Altai Regional Veterinary Center for the Prevention and Diagnosis of Animal Diseases. Two groups of calves with 7 animal units each were selected. The first group was formed by calves born from cows with ketosis. The second group consisted of young calves from clinically healthy cows. The groups were completed as the calves were born.

Ketosis in cows was found by screening the urine for the presence of acetone in it above $0.5 \mathrm{mmol} / 1$ using "Ketogluc" test strips.In biochemical blood tests were additionally performed in positively reacting cows for the content of ketone bodies (KB) and their fractions (acetoacetal, acetone (AcAc), and betta-oxybutyrate (BOB), glucose, and alkaline reserve. Biochemical studies of both groups of calves involved the determination of blood indicators of protein metabolism (total protein, albumins, globulins), glucose, KB, and triglycerides.

The calves ' blood tests were carried out on the $3 \mathrm{rd}, 10$ th and 15 th day after birth. The results obtained were statistically processed. The significance of the differences was determined by the Student's t-test using the paired-comparison method. The difference in values was regarded as significant at $\mathrm{p}<0.05$.

\section{Results and discussion}

Cows with a blood $\mathrm{KB}$ level of $1.2 \mathrm{mmol} / \mathrm{L}$, and a $\mathrm{BOB} / \mathrm{AcAcia}$ ratio, were considered to be suffering from ketosis [9]. The data obtained revealed that the condition of the metabolic processes in the body of young cows with ketosis significantly differs from the studied indicators of the metabolism of young healthy cattle. Throughout the study, the total protein 
in the blood of calves of the experimental group declined and by the 2 nd week of life almost corresponded to the control value, exceeding it by $3.4 \%$. Meanwhile, the difference in the initial values between the groups was $11.4 \%$. The total protein of the control group remained virtually unchanged during all 15 days of observation, and its fluctuations were not significant. The data collected during the experiment are shown in Table 1.

Table 1. Laboratory tests of calves' blood ( $M \pm m, n=7)$

\begin{tabular}{|c|c|c|c|}
\hline \multirow{2}{*}{ Indicators } & \multicolumn{3}{|c|}{ Research days } \\
\cline { 2 - 4 } & 3 days & 10 days & 15 days \\
\hline \multirow{2}{*}{ Experiment group } \\
\hline Total protein, g/l & $60.5 \pm 4.3$ & $58.7 \pm 1.3$ & $56.3 \pm 2.7$ \\
\hline albumins, \% & $58.70 \pm 3.12$ & $57.18 \pm 3.89$ & $57.40 \pm 4.14$ \\
\hline alpha-globulins, \% & $8.88 \pm 3.06$ & $6.50 \pm 1.87$ & $8.46 \pm 3.70$ \\
\hline beta-globulins, \% & $17.06 \pm 3.8$ & $18.76 \pm 6.35$ & $20.59 \pm 5.84$ \\
\hline gamma globulins, \% & $13.26 \pm 2.80$ & $12.22 \pm 2.38$ & $11.42 \pm 1.66$ \\
\hline Triglycerides, mmol/1 & $0.25 \pm 0.05$ & $0.23 \pm 0.04$ & $0.44 \pm 0.02$ \\
\hline Ketone bodies, mmol/1 & $1.05 \pm 0.13$ & $1.19 \pm 0.12$ & $1.26 \pm 0.06$ \\
\hline Glucose, mmol/1 & $5.0 \pm 0.47$ & $7.84 \pm 0.7$ & $5.54 \pm 0.25$ \\
\hline \multicolumn{2}{|c|}{ Control group } \\
\hline Total protein, g/l & $54.3 \pm 3.3$ & $52.8 \pm 1.1$ & $54.6 \pm 2.0$ \\
\hline albumins, \% & $57.22 \pm 1.50$ & $48.31 \pm 6.47$ & $66.68 \pm 3.08$ \\
\hline alpha-globulins, \% & $6.33 \pm 1.73$ & $4.78 \pm 1.89$ & $7.05 \pm 1.50$ \\
\hline beta-globulins, \% & $22.51 \pm 4.31$ & $36.16 \pm 6.9$ & $15.90 \pm 1.65$ \\
\hline gamma globulins, \% & $17.81 \pm 2.80$ & $9.34 \pm 2.05$ & $8.40 \pm 1.90$ \\
\hline Triglycerides, mmol/1 & $0.38 \pm 0.06$ & $0.36 \pm 0.023$ & $0.48 \pm 0.05$ \\
\hline Ketone bodies, mmol/1 & $0.86 \pm 0.07$ & $0.91 \pm 0.12$ & $0.99 \pm 0.16$ \\
\hline Glucose, mmol/1 & $3.13 \pm 0.36$ & $5.24 \pm 0.48$ & $6.33 \pm 0.54$ \\
\hline
\end{tabular}

The blood albumins of the calves of the compared groups did not significantly differ by the 3rd day of life. Meanwhile, the subsequent monitoring days had statistically significant differences. By the 10th day of life, the albumin content in the experimental group was $18.4 \%$ higher, and at the end of the experiment, in the demonstrated calves, their level was already lower than the control - by $13.9 \%$.

In both groups of calves, the change in the alpha-globulin concentration was similar. Meanwhile, though there were no significant differences between the groups, the alphaglobulin content in the young animals of the experimental group was higher than in the similar animals.

The fluctuation dynamics of beta-globulin concentration in calves of the studied groups had the reverse character. On the third day after birth, the level of these globulins in the 
experimental group was $24 \%$ lower than in the control group. In a week (the second study), the content of this indicator in this group raised, but remained lower in the control specimens by $48 \%(\mathrm{p}<0.05)$. By the 15 th day of age, the beta-globulin concentration was again lower in the blood of calves from cows with ketosis.

Gamma globulins in the blood of young animals of both groups declined during all 15 days of follow-up. In the first study, the level of gamma globulins in control calves outweighed that of the experimental animals by $34.3 \%(\mathrm{p}<0.05)$. In the future, the concentration of the considered indicator declined in the control animals more intensively than in the experimental group, and by the second study it was lower than the experimental animals by $23 \%$, and by the final study - by $26.5 \%(\mathrm{p}<0.05)$.

During the whole time of the experiment, the triglyceride content in both groups of calves raised, while remaining at a lower level in the animals of the experimental group. In the beginning of the study, the ratio between the average values of the groups was $34.2 \%$ $(p<0.05)$ lower in the experimental group. On the 10th day of age, the difference was already $36 \%$ in favor of the control. On the 15 th day, the triglyceride concentration in the blood of the experimental group raised significantly (compared to the second study by 1.9 times $(\mathrm{p}<0.01)$, but the level of the control parameter under consideration still outperformed the value of the experimental calves by $8 \%$.

The ketone body concentrations in the young animals of both groups raised throughout the experiment. Furthermore, the level of ketone bodies in the individuals of the experimental group outperformed the concentration of this indicator in the blood of the animals of the same age during the whole experiment. At 3 days of age, the differences in the level were $18 \%(\mathrm{p}<0.05)$ in favor of experienced calves. To the 10 th day, the concentration of acetone bodies in calves raised in both groups, relative to the original data, respectively, in the experimental by $13 \%$, in the control by $6 \%$. The difference in the ketone body content between the groups was 1.5 times $(\mathrm{P}<0.01)$ for the benefit of the experimental young animals. By the age of 2 weeks, ketone bodies were the highest in the calves" blood for the entire study. Meanwhile, the dynamics of the increase in the indicated parameter of the experimental calves outperformed the similar dynamics of the control. Thus, by the 15 th day after birth, the content of acetone bodies increased by $20 \%(p<0.05)$, compared with that at the first observation and by $6 \%$ at the second. The intergroup difference was $21.4 \%$ higher in the experimental young animals compared to the control animals of the same age.

The blood glucose content of calves of both groups grew throughout the experiment, except for the final study, in which calves of the experimental group demonstrated a slight decline in the indicator under consideration. The glucose concentration in the young animals of the experimental group at the beginning of the study significantly outperformed the level of the control indicator and was $59 \%$ higher $(\mathrm{p}<0.05)$. By the 2 nd study, the blood sugar content of the experimental animals kept increasing and was higher than the initial data by $56.8 \%(\mathrm{p}<0.05)$ and outperformed the similar level of the control animals of the same age by $49.6 \%(\mathrm{p}<0.05)$. Notwithstanding the high glucose level in the second study in the experimental calves, by the final study, the intensity of the indicator under consideration significantly reduced relative to the second study by $29.3 \%(p<0.05)$ and was lower than the level of young animals in the control group by $14.3 \%$.

\section{Conclusion}

Calves with metabolic pathology are born from cows with ketosis, which is characterized by dysproteinemia, a high content of ketone bodies and a lower concentration of triglycerides in the blood comparing to the similar animals born from healthy cows. 


\section{References}

1. N. V. Momot, A. A. Kim, N. G. Artemyeva, I. L. Kamelia, L. V. Lapshin and Yu. A. Kolina, Innovative technologies in veterinary medicine, animal husbandry and environmental protection in the Far Eastern Region, 189-192 (2012)

2. N. V. Momot, A. A. Kim, N. G. Artemyeva, I. L. Kamelia, L. V. Lapshin and Yu. A. Momot, Bull. of KrasGAU, 4(79), 197-200 (2013)

3. I. P. Kondrakhin, Vet, 12, 38-40 (1998)

4. A.Trebukhov, A. Elenshleger, IOP Conf. Ser. Ear. \& Environ. Sc, 341, P. 012152 , (2019) doi: 10.1088/1755-1315/341/1/012152

5. A. Ya. Batrakov, A.V. Yashin, T. K. Donskaya, Vet, 7, 43-46 (2017)

6. A. V. Trebukhov, Inn. \& F. Saf, 1(23), 67-70 (2019)

7. V. G. Ryadchikov, O. G. Shlyakhova, D. P. Dubinina, et al, Sc. J. of KubGAUB, 79, 116-135 (2012)

8. A.V. Trebukhov, Bull. of the Alt. St. Agr. Univ, 8(166), 95-99 (2018)

9. L. Kardo. Eff. An. Hus, 1(167), 64-67 (2021)

10. L.N. Simonova, Izv. OGAU, 6(86), 209-2013 (2020)

11. G. V. Shiryaev, T. I. Stanislavovich, V. P. Politov, Bull. of RUDN, 4, 403-416 (2020)

12. A.V. Trebukhov, A. A. Elenschleger, S. P. Kovalev, Ketosis in cows and calves: a study guide, 132 (Lan, Saint Petersburg, 2019)

13. G.G. Mikhin, Izv. OGAU, 3(41), 109-111 (2013)

14. M. F. Vasilev, Immunological principles of complex treatment of cows with ketosis and calves born from them, PbGAVM, Saint Petersburg, 34 (1996) 